would be intercsting to know whether similar results have been found in India and elsewhere within the tropics, or may yet be obtained.

Computing $\delta T$ by means of these formula, and applying the results to the temperatures at Kingston, we have

\begin{tabular}{lllllll} 
& \multicolumn{3}{c}{ Mean } & & Min. \\
Kempshot ... ... & $\ldots$ & $72 \cdot 7$ & $\ldots$ & $\ldots$ & $68 \cdot 0$ \\
Cinchona Plantation & $\ldots$ & $62 \cdot 6$ & $\ldots$ & $\ldots$ & $57 \cdot 5$ \\
Portland Gap... $\ldots .$. & $\ldots$ & $60 \cdot 5$ & $\ldots$ & $\ldots$ & $54 \cdot 7$ \\
Bime Mountain Peak & $\ldots$ & $54 \cdot 4$ & $\ldots$ & $\ldots$ & $45 \cdot 6$
\end{tabular}

which are fairly satisfactory.

Putting $\delta P=30$ inches, the minimum formula gives $-311^{\circ}$ as the temperature of space, the thermometer being shaded from the sun by any spherical body such as the eartia or moon.

Putting $\delta F=30$ inches, the mean formula gives $-8 \mathrm{r}^{\circ}$ as the mean temperature of a body devoid of atmosphere, such as a meteorite pursuing its course in space, or the moon, at the mean distance of the earth from the sun.

An expression for maximum temperatures cannot be as easily deduced; but if the surface of the meteorite or the moon which is turned from the sun be $-31 \mathbf{I}^{\circ}$, and if the mean temperature be $-8 \mathrm{r}^{\circ}$, it follows that the maximum temperature of the surface turned towards the sun must be about $+149^{\circ}$.

Jamaica, Fchruary 12

Maxwelu hat.t.

\section{Electricity and Clocks}

In addition to the plan pointed out by Prof. Sylvanus Thompson (the correct way to repcat from a striking clock to electric bells), I believe I have scen an arrangement in Dublin whereby a single port or going train only is made to strike the hours on an indefinite number of electric bells. I believe this mechanism is a patent.

Sandymount, March $z$

HORLOGE

\section{Top-shaped Hailstones}

ON August 6, 1885, a hailstorm occurred in this neighbourhond, during which two watersponts were scen. After one of these had burst, a fall of hailstones, almost exactly similar to those described by Mr. Middlemiss in your issue of March 3 \{p. 4I 3$\}$, commenced and lasted for some minutes. I do not remember to have noticed that there was a mass of clear ice at the base of the cone, but the handing was very distinct.

Beside the horizontal stratification there was another perpendicular one, giving the hailstone the appearance of being composed of alternate cylinders of clear and white ice. If the hailstones which Mr. Middlemiss saw at Ramnagar showed this peculiarity, he will perhaps be kind enough to communicate the fact through your columns. Sketches of the hailstones which fell in this district were published in the Meteorolagical Record soon after the occurrence, but I cannot give the precise date of the copy.

Facit, Rochdale, March 7

\section{The Present Southern Comet}

Either the present brilliant southern comet is periodic, or one of a large family of comets, moving in similar orbits and possessing marked similarities of structure. Its orbit, as far as an orbit can be determined from the approximate positions of a very indefinite nucleus, is similar to those of the $I 843$ and $I 880$ comets. In Grant's "History of Astronomy" the following description of the 1668 comet occurs :- "It appeared a little above the western horizon. The tail measured $23^{\circ}$ in length, and resembled a huge beam of light. The head was so small as to be scarcely visible. The observations will be represented with sufficient accuracy by the elements of the orbit of the comet of $1843 . "$ A fairly accurate cicscription of the present comet. There are other comets-I6I8, 1689, I702-which possess this strong family likencss. If these comets be not one and the same, they must all have had a common origin. I do not know if it has been noticed that the aphelia of their orbits lie within a few degrees of Sirius. It may be passible that they have all been cjected from that gigantic sun; at any rate, it is impossible that they could have been attracted from nebulous masses lying beyond Sirius.

Lovedale, Suuth Africa, February I

\section{The Earthquake}

I EXAMINED my magnetograms very carefully on the day of the earthquake in North Italy, and I find no trace of any special disturbance on the H.F. trace similar to that on the Kew curve. It may be well to place this on record, as it may aid in fixing the limits of the disturbance.

Stonyhurst College, Blackburn, March 7

\section{CEREBRAL I.OCALISATION ${ }^{1}$}

I.

$\mathrm{T}$ is rather more than ten years since the first edition of this book came under review in the pages of this journal. And it was intrusted to very able hands, for the reviewer was George Henry Lewes, himself an experimentalist in this branch of physiology, and of the highest distinction as a philosopher and psychologist. The review is courteously but unflinchingly hostile : exception is taken to some of the facts and to most of the deductions of the author; although the value of the work, from its richness in suggestions as well as in facts, is ungrudgingly admitted. Mr. Lewes especially complains that the book "is so deficient in the indispensable correctives of counter facts and arguments, that the reader must be cautioned against accepting any position unless elsewhere verified.

From one cause or another there is a disregard of counter evidence, which, in a second edition, I should seriously urge him to rectify. . . This disregard arises from no unfairness, but simply from the one-sidedness which comes from preoccupation with certain views."

The increased size of the work ( $49^{8}$ pages instead of 323 ) is, no doubt, in part due to an endeavour to carry out this suggestion, although the growth of the subject may of itself, in great measure, account for such increase. Indeed, it must be confessed that the characteristic complained of by Mr. Lewes has not by any means entirely disappeared, and the student who may consult its pages must bear in mind that the book still remains the gospel of the functions of the brain "according to Ferrier."

The pervading idea of the work is expressed by the term "localisation of function." It was against this idea (and especially against certain applications of it) that $\mathrm{Mr}$. Lewes brought to bear the full powers of his criticism.

One serious objection which was urged by him against many of Dr. Ferrier's results (those of localised extirpation) was that he was unable to keep the animals alive long ennugh to allow the effects of Disturbance of function to subside, so as to leave only the effects of Removal to be estimated. But the use of antiseptics has now permitted this objection to be removed, since there is no longer, in most instances, the samc difficulty in preserving the animals, as was the case in Dr. Ferrier's first experiments.

It is further urged by the previous reviewer that "neither the effects of Disturbance nor the effects of Removal are to be taken as conclusive evidence that the function disturbed or removed is the function of the organ operated on." [But although not of themselves conclusive, yet if looked at in conjunction with other evidence they may furnish important indications regarding the function of the organ.] Mr. Lewes further affirms that "whenever a function persists or rcappears after the destruction of an organ, this is absolutely conclusive against its being the function of that organ," meaning, of course, of that organ alone. That, in the case of recovery or reappearance, partial or complete, of a lost function, another organ previously possessed of a different function has vicariously taken its place, is a scarcely tenable hypothesis. And yet there are wellrecorded instances of such reappearance: as in the case of Goltz's dogs, which recovered some of the lost power of voluntary movement; and in that of the visual disturbances which are caused by lesions of the occipital lobe, in which

I "The Functions of the Brain." By David Ferrier, M.D., L. . D., F. R.S. Second Edition, re-written and enlarged. (London: Smith, Elder, and Co.,
r886.) 